\title{
Metallurgical and Mechanical Research on Dissimilar Electron Beam Welding of AISI 316L and AISI 4340
}

\author{
A. R. Sufizadeh and S. A. A. Akbari Mousavi \\ School of Metallurgy and Materials Engineering, College of Engineering, University of Tehran, P.O. Box 11155-4563, Tehran, Iran \\ Correspondence should be addressed to A. R. Sufizadeh; sufizadeh@ut.ac.ir
}

Received 20 June 2016; Revised 1 September 2016; Accepted 19 September 2016

Academic Editor: Jörg M. K. Wiezorek

Copyright ( 2016 A. R. Sufizadeh and S. A. A. A. Mousavi. This is an open access article distributed under the Creative Commons Attribution License, which permits unrestricted use, distribution, and reproduction in any medium, provided the original work is properly cited.

\begin{abstract}
Dissimilar electron beam welding of 316L austenitic stainless steel and AISI 4340 low alloy high strength steel has been studied. Studies are focused on effect of beam current on weld geometry, optical and scanning electron microscopy, X-ray diffraction of the weld microstructures, and heat affected zone. The results showed that the increase of beam current led to increasing depths and widths of the welds. The optimum beam current was $2.8 \mathrm{~mA}$ which shows full penetration with minimum width. The cooling rates were calculated for optimum sample by measuring secondary dendrite arm space and the results show that high cooling rates lead to austenitic microstructure. Moreover, the metallography result shows the columnar and equiaxed austenitic microstructures in weld zone. A comparison of HAZ widths depicts the wider HAZ in the 316L side. The tensile tests results showed that the optimum sample fractured from base metal in AISI 316L side with the UTS values is much greater than the other samples. Moreover, the fractography study presents the weld cross sections with dimples resembling ductile fracture. The hardness results showed that the increase of the beam current led to the formation of a wide softening zone as HAZ in AISI 4340 side.
\end{abstract}

\section{Introduction}

It is evident that deployment of dissimilar metals plays the most important part of construction processes due to the technological advances of production in the industry. Dissimilar joints would improve not only products quality in terms of cost but also design and enhancement of the structures' stability. The intrinsic properties of the materials used in dissimilar welding play a major role in determining the weld quality [1].

Electron beam welding is one of the widely used welding methods for joining dissimilar materials in industries. The primary advantage of electron beam welding is its high depth to width ratio which results in a very strong weld. The quality of weld depends upon the parameters, namely, accelerating voltage, beam current, welding speed, focus current, and vacuum level [2].

Electron beam welding has high power density and consequently led to small heat affected zone and high heating and cooling rates. The spot size of the EBW can vary between $0.2 \mathrm{~mm}$ and $13 \mathrm{~mm}$, though only smaller sizes are used for welding. The depth of penetration is proportional to the amount of power supplied but is also dependent on the location of the focal point. Penetration is maximized when the focal point is slightly below the surface of the work piece [3].

The AISI 4340 stainless steel is of those high strength low alloy steels that their strengths are achieved with appropriate heat treatments [4]. It has good weld ability and is usually welded by the GTAW process [5].

Resistance welding and many other arc welding processes are used to weld austenitic stainless steels. But the resistance to corrosion and cracking in austenitic stainless steels are the major problems where careful selection on welding process or any other further solution is required. The corrosion properties of AISI 316L stainless steel are enhanced by addition of molybdenum. The AISI 316L stainless steel microstructure contains austenite with a little ferrite [6].

Basically, in dissimilar welding, the degree of dilution of each material in the weld bead is very important. This matter is also one of the influential parameters in the weld microstructures in the laser welding process [7]. The degree of dilution of the weld can be achieved by adjusting 
beam-focal point position relative to the joint interface of the weld. There is a possibility that the beam diameter is deviated away from the interface during laser welding in practice. Positioning of the focused beam by CNC facilitates location control and chemical compositions of the weld. This procedure requires close tolerances during the preparation of the joint [8].

Arivazhagan et al. studied the microstructure and mechanical properties of AISI 304 stainless steel and AISI 4140 low alloy steel joints by electron beam welding (EBW). The yield strengths of weldments performed by EBW were higher than those carried out by GTAW. In the weldments performed by EBW, the failures occurred on the HAZ of the AISI 4140 steels [9].

The fatigue performance of an electron-beam welded joint between AISI 4140 and AISI 316L steel has been investigated by Çalik et al. Results indicated that a good strength weld can be achieved between the two dissimilar steels by electron beam welding with a fatigue limit approaching $190 \mathrm{MPa}$, which is a value between the fatigue limits of the base materials. The microstructure of the electron-beam welded dissimilar AISI 4140-AISI 316L joint consisted of both columnar and equiaxed austenite grains in the weld interface [10].

\section{Research Method}

In this study, welding was performed with the electron beam welding machine. Table 1 shows the chemical compositions of the AISI 4340 low alloy high strength steel and AISI 316L austenitic stainless steel obtained by wave dispersive X-ray fluorescence spectroscopy. Table 2 presents the mechanical properties of base metals.

Figures 1(a) and 1(b) depict the microstructures of the AISI 316L stainless steel and the AISI 4340 steel. The typical picture of the welded sample is shown in Figure 1(c) in which a butt square weld joint was used. The thickness of the base metals at the joint cross section was $0.5 \mathrm{~mm}$. No filler metal was used for electron beam welding and the welding was performed autogenously.

In order to investigate the effects of EBW parameters on the weld microstructures, the welding tests were (conducted) carried out with selected welding parameters according to Table 3.

The chemical etching was performed for optical examinations with the solution containing $40 \mathrm{~mL}$ methanol, $20 \mathrm{~mL}$ choleric acid, and $15 \mathrm{~mL} \mathrm{HNO}_{3}$ for 40 seconds. The electrochemical etching was carried out for SEM examinations with $6 \mathrm{~V}$ voltage and $\mathrm{NaOH}$ solution in 20 seconds. Also in order to reveal the microstructure and phases, the optical and scanning electron microscopy and $\mathrm{X}$-ray diffraction were implemented.

The EDS analysis was carried out to investigate the variations (in weight $\%$ ) of the main chemical elements across the weld cross section.

The tensile tests were carried out according to ASTM E8 for subsize specimen [11]. Figures 2(a) and 2(b) show the schematic dimensions of tensile test specimen and typical tensile test welded sample, respectively.
The Vickers microhardness was carried out with applying $100 \mathrm{gr}$ load in 15 seconds. The microhardness profiles were obtained across the 316L stainless steel, the weld zone, and the 4340 steel. Figure 3 shows the schematic of the microhardness points investigated across the welding zone.

\section{Results and Discussion}

\subsection{The Effects of Beam Current on Weld Properties}

3.1.1. The Effects of Beam Current on Weld Geometry. Beam current is one of the most vital parameters in the electron beam welding process. Experiments have been conducted to note its effects on the depth of penetration.

Trials were conducted, to determine the range of beam current that can be used for a thickness of $0.5 \mathrm{~mm}$. Hence, the range of beam currents is determined to be in between $1.6 \mathrm{~mA}$ and $4 \mathrm{~mA}$. At constant voltage, weld focus value, speed of $0.2 \mathrm{~cm} / \mathrm{min}$, duration, and vacuum, beam current was varied as tabulated in Table 3 and observations were made.

According to previous investigation [12], the heat input was directly increased with beam current. The results were shown in Figure 4 . The depth and width of the weld were increased with beam current. The width of the weld is more influential to the beam current than the depth of the weld (see Figure 4). The maximum depth was obtained for 2.8, 3.4, and $4 \mathrm{~mA}$ and was full penetration weld with $500 \mu \mathrm{m}$ depths. The maximum width for the $4 \mathrm{~mA}$ beam current was $1950 \mu \mathrm{m}$. In equal weld depths, the beam current increase could cause the excessive increase of weld widths which is not desirable in such low heat input process. Therefore, sample number 3 $(2.8 \mathrm{~mA})$ was selected as the optimum one, since the penetration of all three samples $(2.8,3.4$, and $4 \mathrm{~mA})$ is the same.

3.1.2. The Effects of Beam Current on Weld Microstructure. Based on Figure 5, fine grained austenitic microstructures are seen as the dissimilar weld microstructure. The electron beam welding parameters play important role on weld microstructure and mechanical properties due to their effect on heat input. The effects of beam current on weld grain size were investigated.

Figure 5 shows that the weld grain size increases with beam current. The reason can be attributed to the increase of power and heat input [13] which reduces the cooling rate. Therefore, there is enough time for excessive grain growth in the weldment solidification period. Moreover, according to Figure 6 , the observation showed that increasing the beam current values more than $2.8 \mathrm{~mA}$ led to significant grain growth rate but in lower beam current values the gradual growth was accrued. The reason can be attributed to the excessive increase of beam current only which led to increase in weld volume and decrease in cooling rate. At this condition, there is much more time for growth stage during solidification.

3.2. The Microhardness Tests of the Welded Specimen. Figure 7 shows the microhardness profiles. The $x$-axis in Figure 7 shows the locations where microhardness tests were carried out. These locations are shown in Figure 3. 
TABLE 1: The chemical composition of the base metals.

\begin{tabular}{lccccccccccc}
\hline Material elements & $\mathrm{Si}$ & $\mathrm{P}$ & $\mathrm{S}$ & $\mathrm{C}$ & $\mathrm{Mo}$ & $\mathrm{Mn}$ & $\mathrm{Ni}$ & $\mathrm{Cr}$ & $\mathrm{Fe}$ & $\mathrm{Cr}_{\mathrm{eq}}$ & $\mathrm{Ni}_{\mathrm{eq}}$ \\
\hline AISI 316L & 0.39 & 0.031 & 0.005 & 0.027 & 2.89 & 1.84 & 10.65 & 16.62 & 68.95 & 19.9 & 12.38 \\
AISI 4340 & 0.35 & 0.010 & 0.001 & 0.391 & 0.21 & 0.79 & 1.90 & 0.88 & 74.79 & 1.44 & 13.99 \\
\hline
\end{tabular}

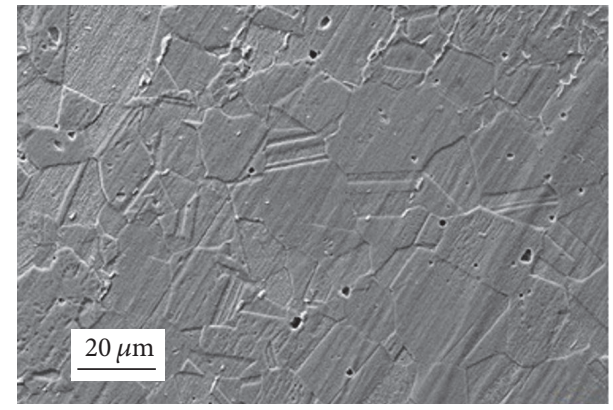

(a)

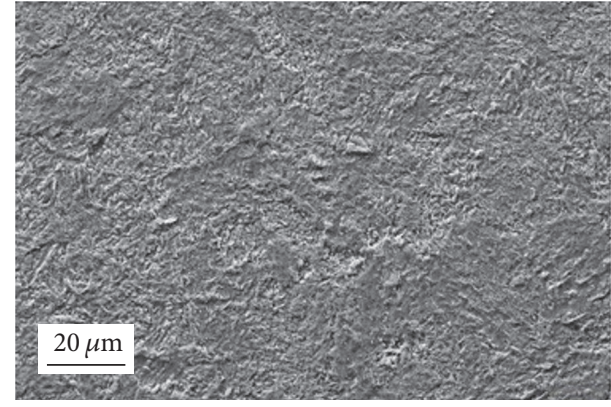

(b)

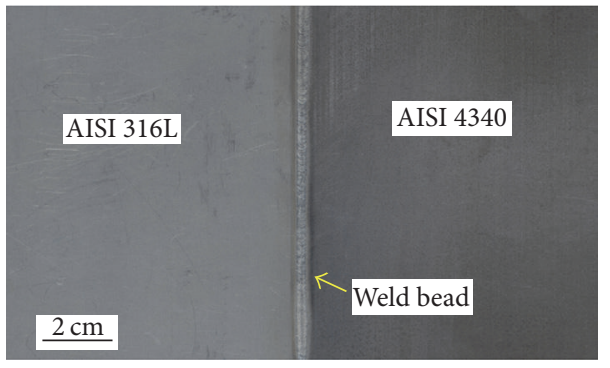

(c)

FIgURe 1: (a) Microstructures of AISI 316L. (b) Microstructures of AISI 4340 steel. (c) The welded joint macrograph.

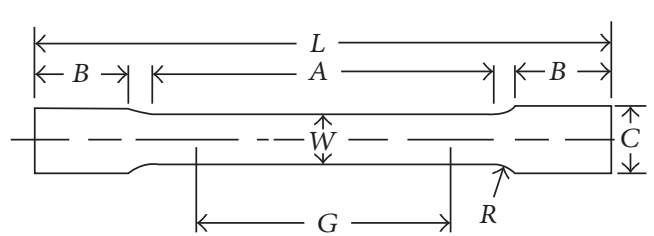

(a)

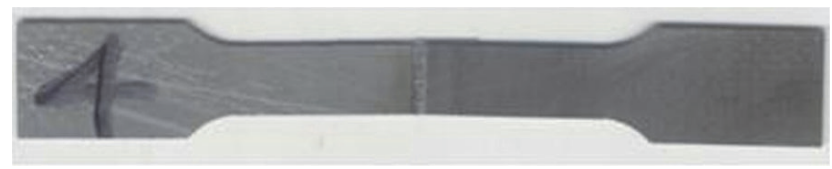

(b)

Figure 2: (a) Schematic of tensile test sample. (b) Tensile test sample [11]. G: gage length, $W$ : width, $T$ : thickness, $R$ : radius of fillet, min, $L$ : overall length, min, $A$ : length of reduced section, min, $B$ : length of grip section, $\min$, and $C$ : width of grip section, approximate.

According to Figure 7, if the austenitic weld microstructure is formed, the magnitude of the weld microhardness will be between those of base metals (450-550 HV). On the other hand, the microhardness of the weld zone is greater than that of the AISI 316L stainless steel base metal due to producing fine grain austenitic weld microstructure. The microhardness of the weld zone is lower than that of the AISI 4340 steel base
TABLE 2: The mechanical properties of the base metals.

\begin{tabular}{lccc}
\hline Alloy & $\begin{array}{c}\text { Ultimate tensile } \\
\text { strength }(\mathrm{MPa})\end{array}$ & $\begin{array}{c}\text { Yield strength } \\
(\mathrm{MPa})\end{array}$ & Elongation\% \\
\hline AISI 316L & 515 & 190 & 45 \\
AISI 4340 & 744 & 475 & 22 \\
\hline
\end{tabular}

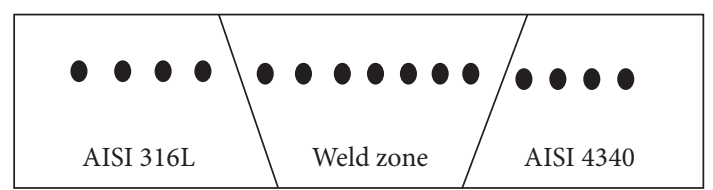

FIgURE 3: The schematic microhardness profiles.

metal because the austenitic weld microstructure is softer than the martensitic structure of the AISI 4340 steel base metal. The fluctuation of hardness profile in weld center line is the result of the change of solidification mode from columnar dendrite to equiaxed dendrite by transition from fusion line to center line according to Figure 16.

In the HAZ near AISI 316L stainless steel side, the hardness is similar to base metal. However, on the other side (near the AISI 4340 steel) the softened zone is observed. The 
TABLE 3: The parameters for electron beam welding process.

\begin{tabular}{|c|c|c|c|c|c|}
\hline Sample number & Voltage, KV & Weld focus value, Amps & Beam current, $I, \mathrm{~mA}$ & Vacuum, Torr & Speed, $\mathrm{cm} / \mathrm{s}$ \\
\hline 1 & $45 \mathrm{KV}$ & $2.2 \mathrm{~A}$ & $1.6 \mathrm{~mA}$ & $5 \times 10^{-4}$ & $0.2 \mathrm{~cm} / \mathrm{s}$ \\
\hline 2 & $45 \mathrm{KV}$ & $2.2 \mathrm{~A}$ & $2.2 \mathrm{~mA}$ & $5 \times 10^{-4}$ & $0.2 \mathrm{~cm} / \mathrm{s}$ \\
\hline 3 & $45 \mathrm{KV}$ & $2.2 \mathrm{~A}$ & $2.8 \mathrm{~mA}$ & $5 \times 10^{-4}$ & $0.2 \mathrm{~cm} / \mathrm{s}$ \\
\hline 4 & $45 \mathrm{KV}$ & $2.2 \mathrm{~A}$ & $3.4 \mathrm{~mA}$ & $5 \times 10^{-4}$ & $0.2 \mathrm{~cm} / \mathrm{s}$ \\
\hline 5 & $45 \mathrm{KV}$ & $2.2 \mathrm{~A}$ & $4.0 \mathrm{~mA}$ & $5 \times 10^{-4}$ & $0.2 \mathrm{~cm} / \mathrm{s}$ \\
\hline
\end{tabular}

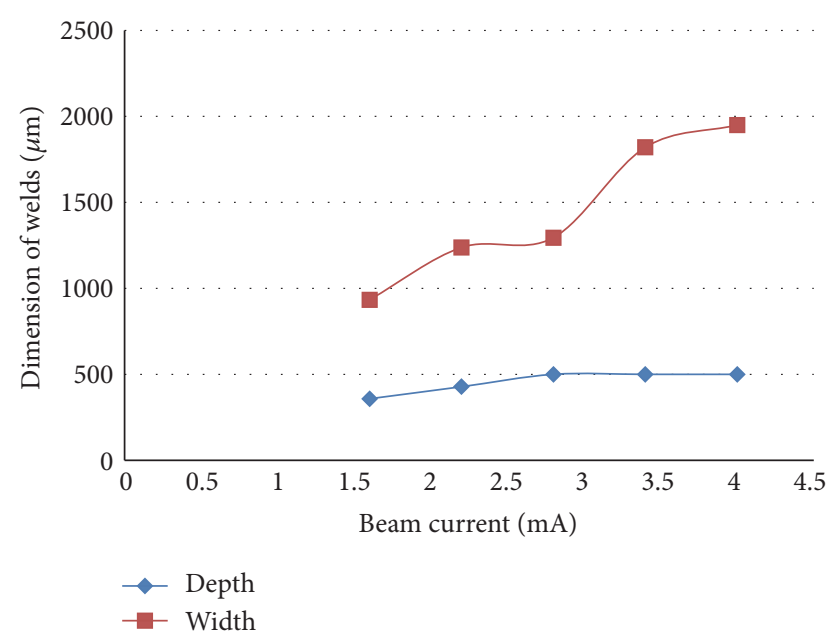

FIGURE 4: The effect of beam current on welds geometry.

reason can be attributed to producing coarse grained softening zone in the HAZ near the fusion boundary, according to Figure 17(b). The minimum hardness occurred on HAZ sample number 5 . This is attributed to the beam current value in this sample which is the highest among all samples. So the heat affected zone was much longer exposed to high temperature and wider softening zones were created.

3.3. The Tensile Tests of the Welded Samples. The engineering stress-engineering strain curves obtained by the tensile tests of the transverse welded full penetration samples (numbers 3, 4, and 5) are shown in Figure 8. According to the results of the tensile tests, samples number 3 (optimum depth/width ratio) and number 4 fractured above $515 \mathrm{MPa}$ (the ultimate tensile strength of the AISI 316L stainless steel). On the other hand, it was observed that the strength magnitude of EBWwelded samples was lower than that of the AISI 4340 steel and higher than that of the AISI 316L stainless steel. These results were confirmed with the effect of producing fine grained microstructure in the austenitic weld zone. Figure 9 shows the fracture locations in the samples. Samples numbers 3 and 4 fractured in the AISI 316L stainless steel sides while sample number 5 was fractured on HAZ in side of AISI 4340. The reason for low tensile strength for sample number 5 can be described. The beam current of sample number 5 is the highest value so that the wide softening zone in HAZ was created. The failure occurred in the softening zone in heat affected zone. These results are in good agreement with the hardness results of the HAZ in AISI 4340 side, shown in Figure 7.
Figure 10 shows the fractography analysis obtained by SEM. The dimples in Figures 10(a) and 10(b) verified the ductile fracture behavior of AISI $316 \mathrm{~L}$ as the base metal in samples numbers 3 and 4 . Moreover, the dimples on Figure 10(c) shows ductile fracture behavior of AISI 4340 as the HAZ in sample number 5.

3.4. The Microstructure Investigations. Considering the results obtained at previous sections, one may conclude that the optimum parameters were applied on sample number 3 from mechanical properties and weld geometry point of view. Therefore, in this section the metallurgical properties, solidification patterns, and the microstructure of sample number 3 were studied.

3.4.1. The Microstructure Prediction by Schaefler Diagram. The dissimilar weld microstructures prediction of Schaeffler diagram (Figure 11) with those achieved by the experiments had been investigated by the EDS analyses of $\mathrm{Cr}, \mathrm{Ni}, \mathrm{Mn}, \mathrm{C}, \mathrm{Si}$, and Mo elements for the points shown in Figure 12. The EDS results were used to calculate $\mathrm{Cr}$ and $\mathrm{Ni}$ equivalent content for all three regions considered (Table 4).

$$
\begin{aligned}
& \mathrm{Cr}_{\mathrm{eq}}=\mathrm{Cr} \%+\mathrm{Mo} \%+1.5 \mathrm{Si} \%+0.5 \mathrm{Cb} \% \\
& \mathrm{Ni}_{\mathrm{eq}}=\mathrm{Ni} \%+30 \mathrm{C} \%+0.5 \mathrm{Mn} \%
\end{aligned}
$$

According to the Schaeffler diagram (see Figure 11), the austenite + martensite microstructures of are predicted; however, Figure 12 shows that the full austenitic microstructure is produced in the weld microstructures. The reason can be attributed to high cooling rate in EBW process which causes changes in the solidification mode from ferritic to austenitic mode according to Figure 13(a) [14]. The results of Figure 12 are in good agreement with previous investigations $[15,16]$.

3.4.2. The Calculation of Welding Cooling Rate. In order to study the cooling rate of sample number 3 , the measurement of secondary dendritic arm space (SDAS) was carried out. According to the investigation of [17], the following formula was explained for the relationship between SDAS and cooling rate:

$$
\mathrm{SDAS}=K \cdot \dot{T}^{-n}
$$

where $\dot{T}$ is cooling rate $(\mathrm{K} / \mathrm{s})$ and $K$ and $n$ are material constants which are approximately 100 and 0.5 for austenitic microstructure [17]. Table 5 shows the results of SDAS and cooling rate measurements. The results reveal that, based on the high cooling rate $(816 \mathrm{~K} / \mathrm{s})$, referring to Figure $13(\mathrm{a})$, the 

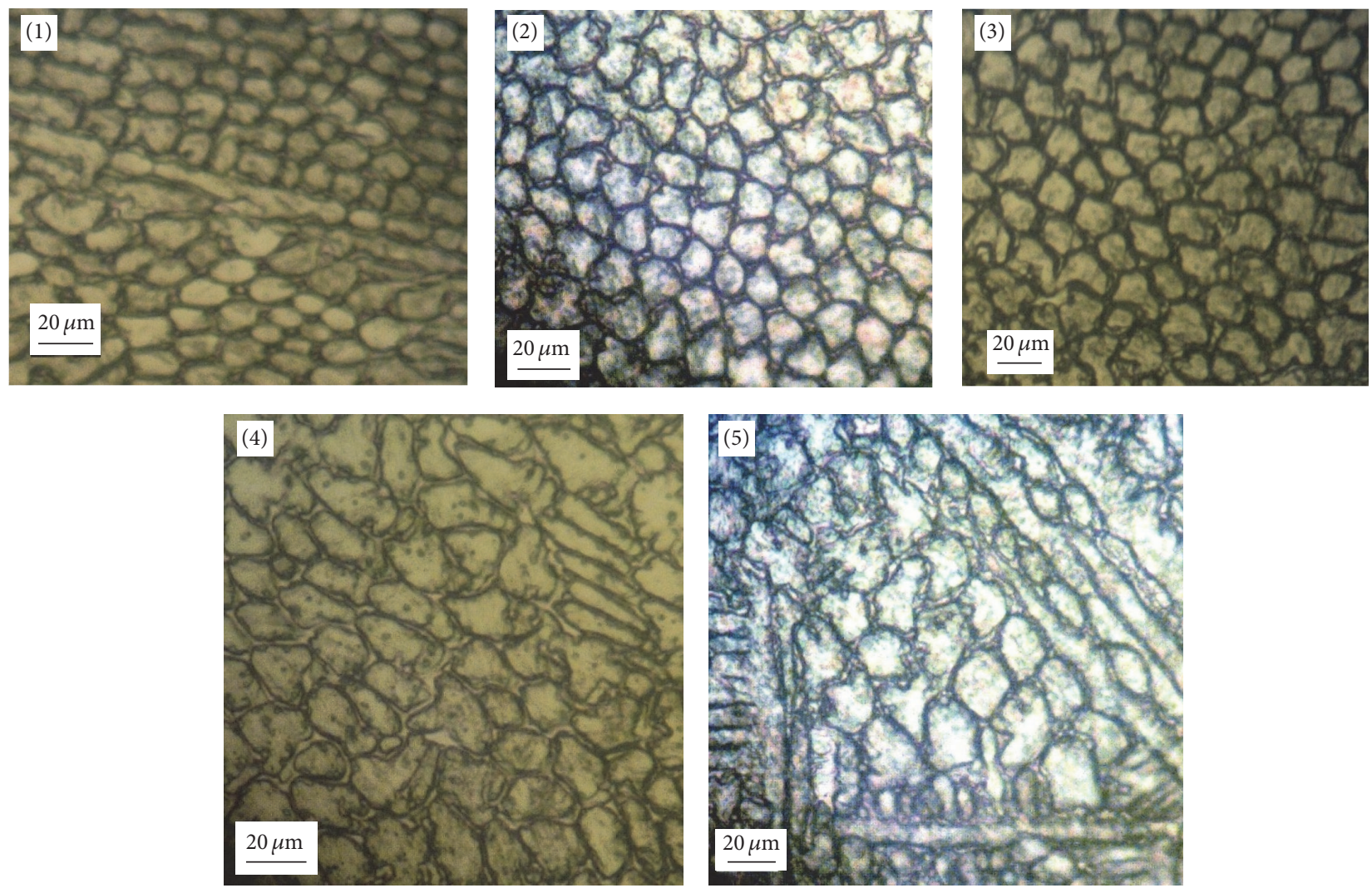

FIGURE 5: The grain size from welded microstructure.

TABLE 4: The calculation based on Schaeffler diagram for prediction of welds microstructures for sample number 3.

\begin{tabular}{lcccc}
\hline Sample location & $\mathrm{Cr}_{\mathrm{eq}}$ & $\mathrm{Ni}_{\mathrm{eq}}$ & Predicted microstructure & Actual microstructure \\
\hline Assumption & 11.2 & 13.2 & $\mathrm{~A}+\mathrm{M}$ & $\mathrm{A}$ \\
dilution (50\%) & 8.1 & 12.8 & $\mathrm{M}$ & $\mathrm{A}$ \\
Figure 12(d) (near 4340) & 17.8 & 10.6 & $\mathrm{~A}+\mathrm{M}+\mathrm{F}$ & $\mathrm{A}$ \\
Figure 12(b) (near 316L) & 15.5 & 11.3 & $\mathrm{~A}+\mathrm{M}$ & $\mathrm{A}$ \\
Figure 12(c) (weld center) & & & \\
\hline
\end{tabular}

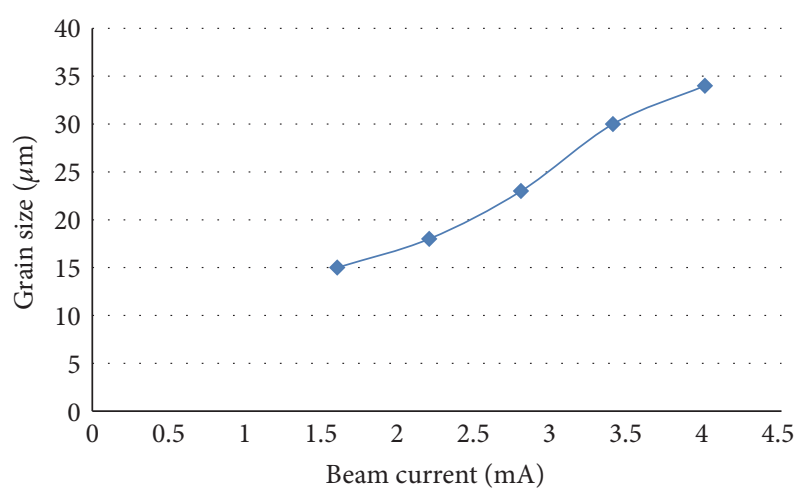

Figure 6: The effect of beam current on weld zone grain size.

austenite dendrite tip temperature is higher than ferrite and this attributed to change solidification mode from austenite + martensite to fully austenite. High cooling rate effect is in
TABLE 5: The results from SDAS and cooling rate measurements for sample number 3 .

\begin{tabular}{lccc}
\hline DAS $(\mu \mathrm{m})$ & SDAS $(\mu \mathrm{m})$ & SDA thickness $(\mu \mathrm{m})$ & Cooling rate $(\mathrm{K} / \mathrm{s})$ \\
\hline 5.99 & 3.5 & 0.8 & 816 \\
\hline
\end{tabular}

accordance with formation of austenitic microstructures in Figure 13(b), which is also in accordance with the pervious investigations $[15,16]$.

3.4.3. The Microsegregation in Dendritic Microstructure. In the next step, the EDS analyses for sample number 3 were carried out in order to investigate the microsegregation during solidification and differences of percent of alloys element in subgrain, dendrites, and interdendritic spaces were done. The results were shown in Figure 14 and Table 6. According to Table 6 at point A (subgrain boundary), the percent of ferrite promotion such as $\mathrm{Cr}$ and Mo was $13.39 \%$ and 3.23\%, 


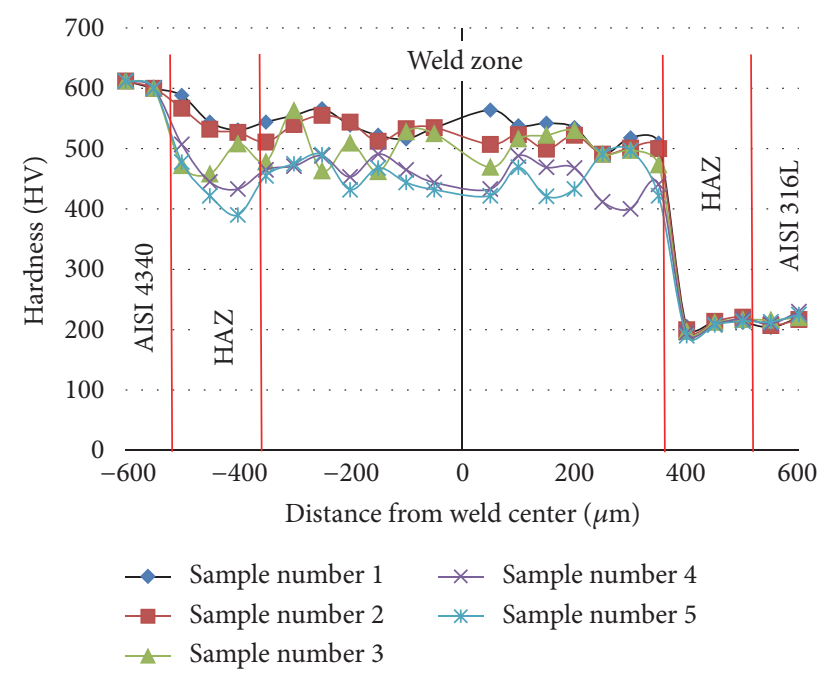

Figure 7: The profile from hardness tests for EBW weld samples.

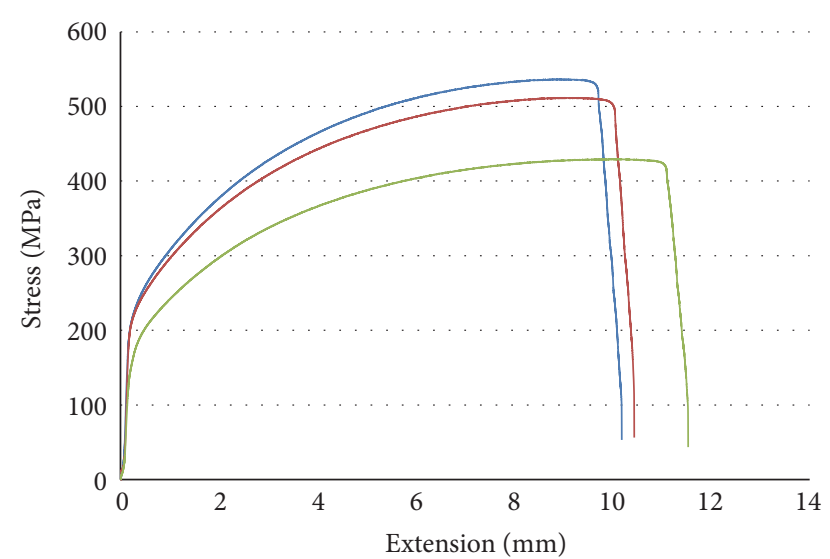

Sample number 3
- Sample number 4
Sample number 5

FIGURE 8: The tensile tests curves for EBW full penetration weld samples.

TABLE 6: The EDS analyses from subgrain boundary and subgrain spaces in the weld zone (sample number 3 ).

\begin{tabular}{lcccc}
\hline \multirow{2}{*}{ Element } & \multicolumn{4}{c}{ Weight } \\
& $\mathrm{A}$ & $\mathrm{B}$ & $\mathrm{C}$ & $\mathrm{D}$ \\
\hline Silicon & 0.44 & 0.66 & 0.3 & 0.6 \\
Chromium & 13.39 & 10.38 & 11.33 & 12.26 \\
Manganese & 0.77 & 0.11 & 0.01 & 0.01 \\
Nickel & 7.25 & 5.92 & 7.61 & 6.03 \\
Molybdenum & 3.23 & 1.75 & 1.84 & 2.55 \\
\hline
\end{tabular}

respectively, while in the matrix and point $\mathrm{B}$ that element percent was reduced to $10.38 \%$ and $1.75 \%$, respectively.

These characterizations are the consequence of the austenite dendrites growth during solidification and also the reduction of the solubility of ferrite promotions elements

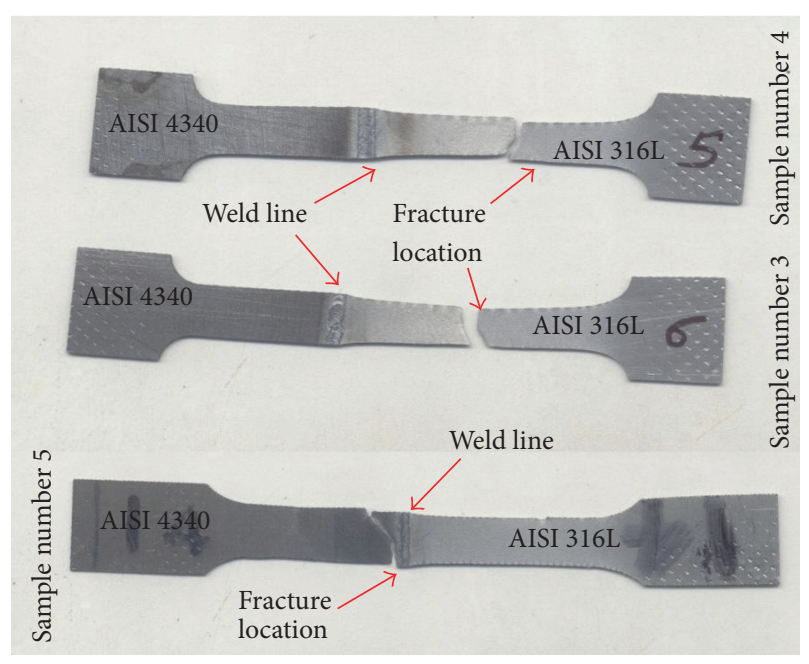

FIGURE 9: The fracture locations of EBW-welded specimens after tensile tests.

TABLE 7: The EDS analyses from matrix and grain boundary in AISI 316L heat affected zone side.

\begin{tabular}{lcc}
\hline Element & $\begin{array}{c}\text { Weight percent (\%) } \\
\text { at point E }\end{array}$ & $\begin{array}{c}\text { Weight percent (\%) } \\
\text { at point F }\end{array}$ \\
\hline Silicon & 0.4 & 0.5 \\
Chromium & 19.5 & 16.4 \\
Manganese & 0.8 & 0.9 \\
Nickel & 7.1 & 10.5 \\
Molybdenum & 2.9 & 2.2 \\
\hline
\end{tabular}

such as $\mathrm{Cr}$ and Mo. In this process, the austenitic former elements are concentrating on the dendritic structures and the ferritic former elements are traveling to interdendritic structures. In order to investigate ferrite formation in interdendritic spaces, the XRD test (Figure 15) was carried out. The results show that no ferrite phases were created and the microstructure is completely austenite. This result is in accordance with Figures 12 and 13, which is also conforming to the previous investigations $[15,16]$.

According to the EDS results (Table 7), the secondary dendritic arm space (SDAS) shows that the microsegregation was less than dendritic arm space (DAS) and the percent of $\mathrm{Cr}$ and $\mathrm{Mo}$ was $12.24 \%$ and $2.54 \%$, respectively. The smaller diffusion zone, solute redistribution of elements in dendrite tips, and very high cooling rate are the major factors resulting in formation of SDAS and so the reduction of microsegregation in SDAS.

3.4.4. The Solidification Mode in the Weld Zone. According to Figure 16, transitions from fusion line to center line lead to changing the microstructure of weld from columnar dendrites to equiaxed dendrites. These results were attributed to the low growth rate $(R)$ in the fusion boundary and it increases from the fusion boundary to the weld centerline. On the other hand, the thermal gradient $(G)$ is minimum in the weld center and maximum in the fusion boundary. Therefore, 


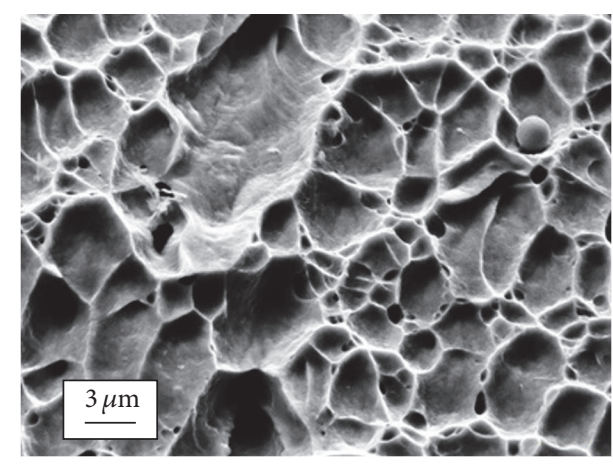

(a)

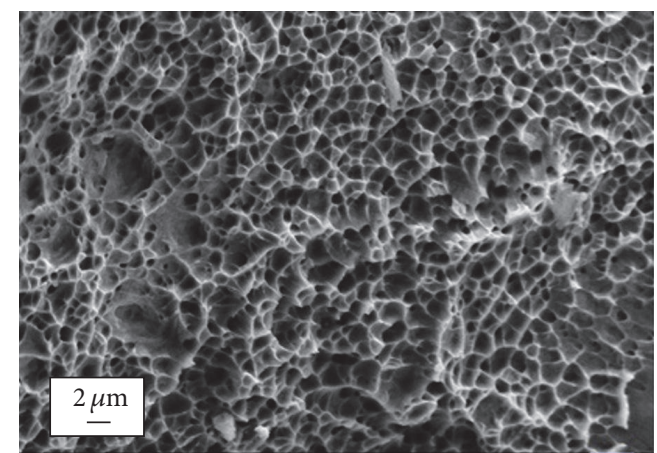

(b)

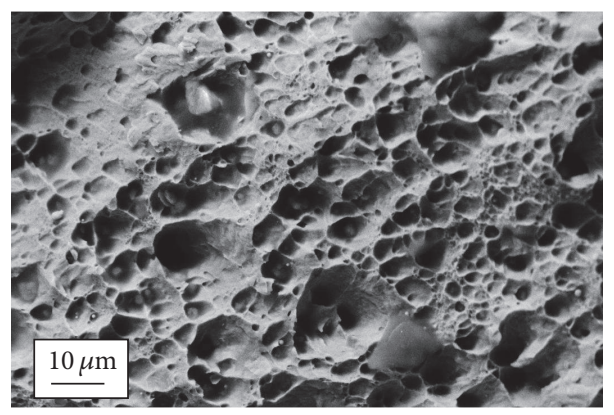

(c)

FIGURE 10: The fractography of welded samples: (a) sample 3; (b) sample 4; (c) sample 5.

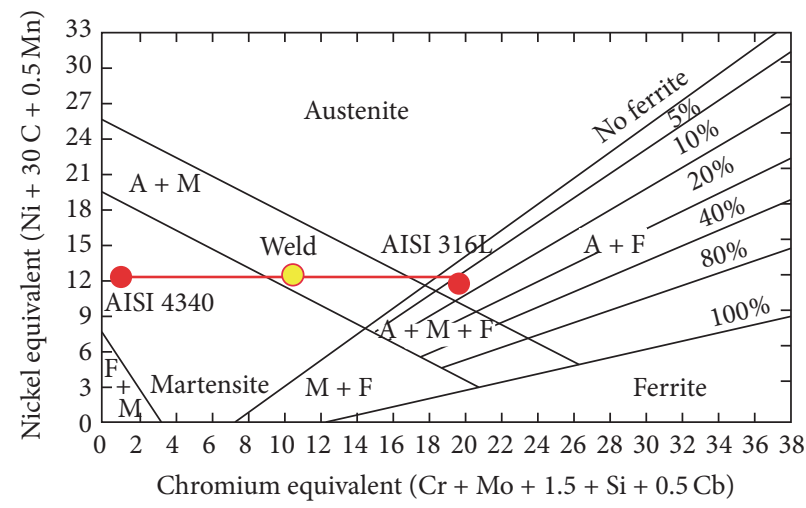

FIGURE 11: The predicted weld microstructure by Schaeffler diagram [14].

the $G / R$ ratio which determines the solidification mode of the microstructure is maximum in the fusion boundary and minimum in the weld center line. Therefore, the microstructure is columnar dendrite in the fusion boundary which changes to equiaxed dendrite structure by reducing the $G / R$ ratio in the center of the weld. This change attributed to fluctuation of hardness in weld center line on the microhardness diagram in Figure 7.

3.5. The Heat Affected Zone (HAZ) Microstructure. According to Figure 17(a), the close zone near fusion line formation of new phase was detected in HAZ area on AISI 316L side. Two phenomena would probably occur: the formation of $\mathrm{Cr}$ carbide and ferrite. In this zone attributed to low percent of carbon, the probability of Cr carbide formation was too low which is in accordance with the results of EDS analyzes depicted in Table 7 with no formation of Cr carbide. However, according to the EDS results in Figure 18 and Table 7, the increase in amount of $\mathrm{Cr}$ in white zone comparison with matrix (in Figure 18) will increase the probability of formation of ferrite phase in grain zone. On the other hand, the absence of grain growth in HAZ (the lock austenite grain boundaries by ferrite) makes this phenomenon more feasible and probable.

In order to investigate formation of ferrite phase, the XRD test was done (Figure 19). The results show little percent 


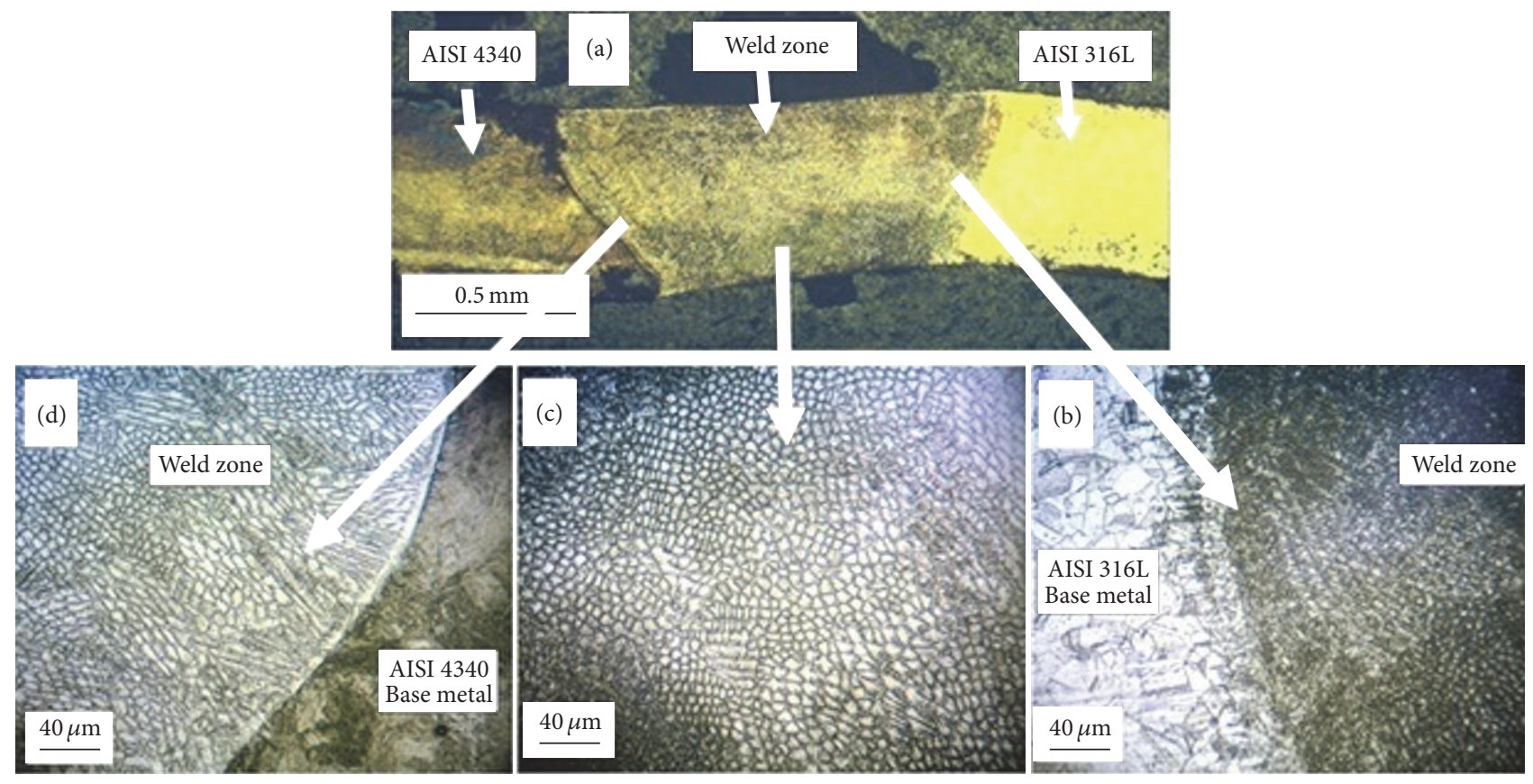

FIGURE 12: The weld microstructure for sample number 3: (a) weld macrograph; (b) near AISI 316L; (c) center of weld; (d) near AISI 4340.

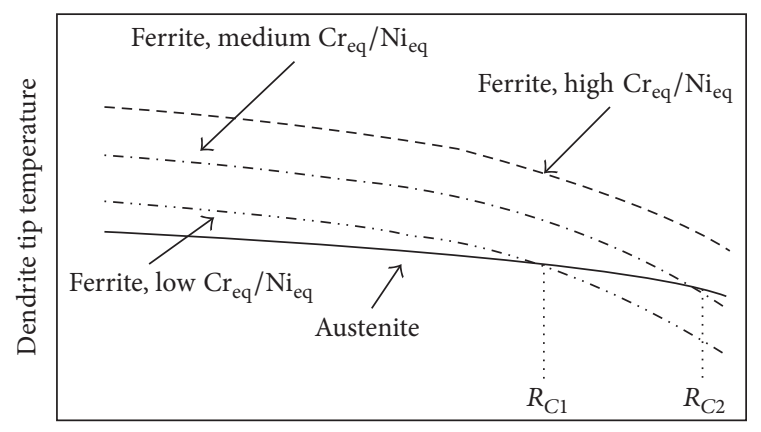

Solidification growth rate

(a)

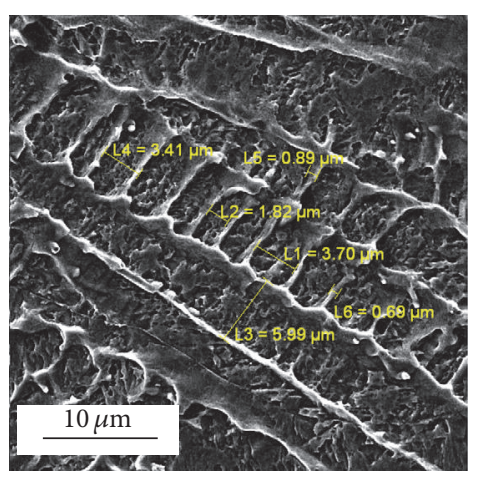

(b)

FIgURE 13: The SDAS and DAS sizes for EBW weld zone for sample number 3.

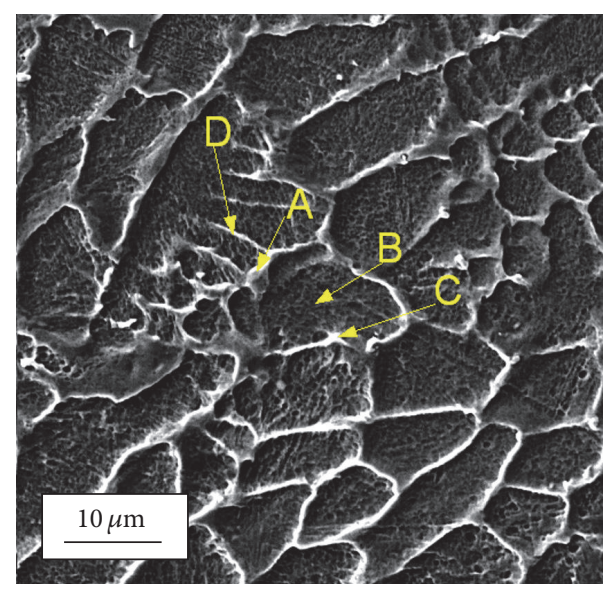

FIGURE 14: The EDS points to investigate microsegregation in subgrain boundary and subgrain spaces in the weld zone (sample number 3). 


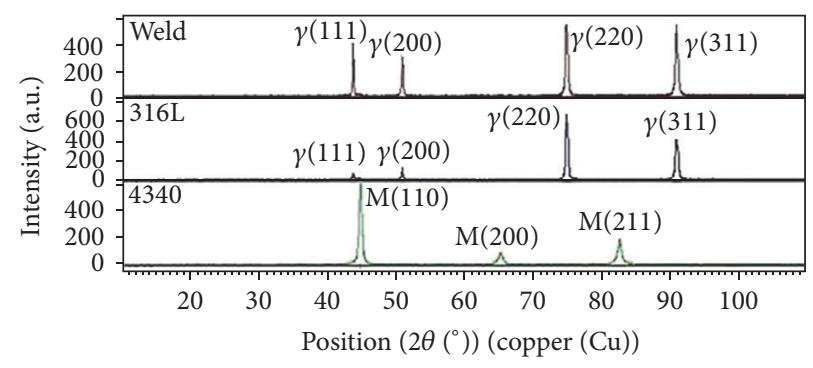

FIGURE 15: The XRD pattern from weld zone (sample number 3) and base metals.

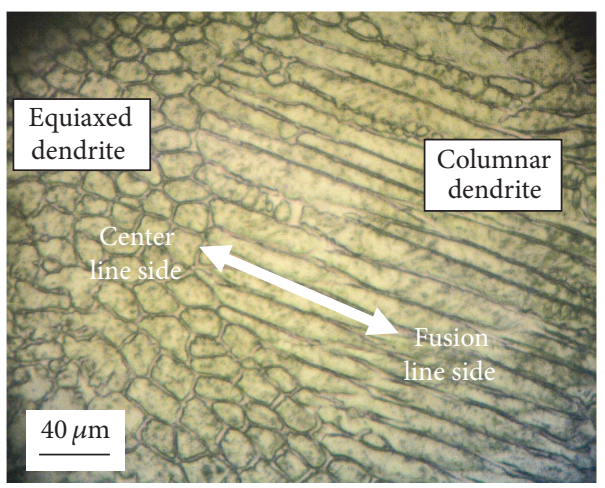

FIGURE 16: The change solidification mode by transition from fusion line to center line.

ferrite was created. This result strengthens the possibility of the formation of ferrite phase in white zone according to Figure 18 .

According to Figure 17, the HAZ widths are different in the AISI 316L and AISI 4340 sides, 50 and $10 \mu \mathrm{m}$, respectively. The reason was due to using different materials with different heat conduction coefficients and also due to performing various heat inputs. Based on Figure 17, the HAZ width in AISI 316L stainless steel side was 3 or 4 times greater than that of AISI 4340 steel side. The major reason is attributed to the different heat conduction coefficients of AISI 316L stainless steel and AISI 4340 steel. The heat conduction coefficients were 44.5 and $16.3 \mathrm{~W} / \mathrm{m} \cdot \mathrm{K}$ for AISI 4340 steel and AISI 316L stainless steel, respectively. In fact, the heat conduction coefficient of AISI 4340 is approximately 3 times greater than that of AISI 316L stainless steel. Therefore, the heat input induced in the materials leads to producing smaller HAZ size in the AISI 4340 steel side than the HAZ size in the AISI 316 stainless steel side.

Figure 17(b) shows the heat affected zone on AISI 4340 base metal side. The small narrow zone with approximately $10 \mu \mathrm{m}$ width containing large grains was detected close to fusion line. This attributed to low heat input in electron beam welding process. The softening zone in this sample was too small and can be ignored. These results were in accordance with microhardness results in Figure 7. Moreover according to Figure 17(c), the HAZ width in AISI 4340 side for sample number 5 was $45 \mu \mathrm{m}$. The softening zone with coarse microstructure was detected which is in accordance with microhardness results (Figure 7) and tensile test results
(Figures 8, 9, and 10). This could be attributed to high beam current value in sample number 5 as was explained in Sections 3.1.1 and 3.1.2.

\section{Conclusions}

This paper presents electron beam welding of AISI $316 \mathrm{~L}$ stainless steel and AISI 4340 low alloy steel. The welding process was carried out by changing the beam current values from $1.6 \mathrm{~mA}$ to $4 \mathrm{~mA}$. The depth and width of the weld were increased with beam current. The full penetration weld with $500 \mu \mathrm{m}$ depth was obtained at $2.8,3.4$, and $4 \mathrm{~mA}$. The microhardness values of weld zone were greater than that in the AISI 316L stainless steel due to fine grain austenitic formation in weld microstructure. In the HAZ near the AISI 4340 steel, the softening zone was observed. The tensile tests results showed that samples 3 and 4 fractured from base metal in AISI 316L side with the UTS values much greater than the UTS values of sample number 5 which fractured from HAZ in AISI 4340 side due to high beam current value and wide softening zone occurred in sample number 5 . The full austenitic microstructure was produced in the weld zone. The SDAS measurements showed the high cooling rate during the process. Such cooling rate is in accordance with the formation of austenitic microstructure. The low heat input resulted in formation of small HAZ and the absence of $\mathrm{Cr}$ carbide. The study showed that the HAZ width in the AISI $316 \mathrm{~L}$ stainless steel side was 3 or 4 times greater than that of the AISI 4340 side. The optimum beam current was obtained at $2.8 \mathrm{~mA}$. 


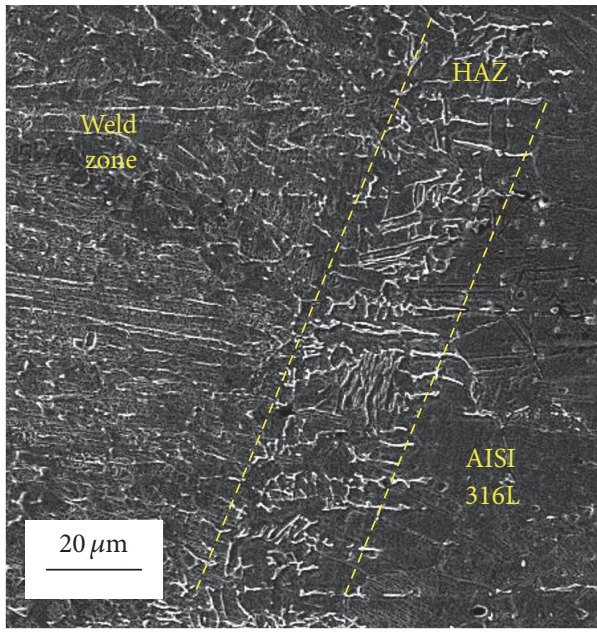

(a)

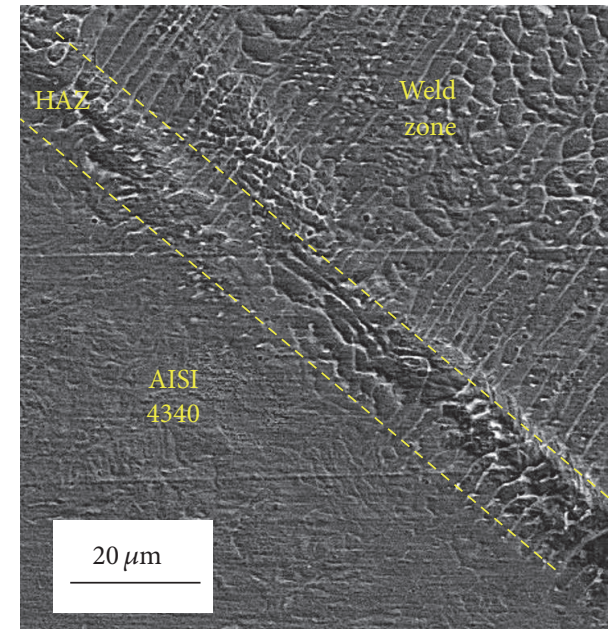

(b)

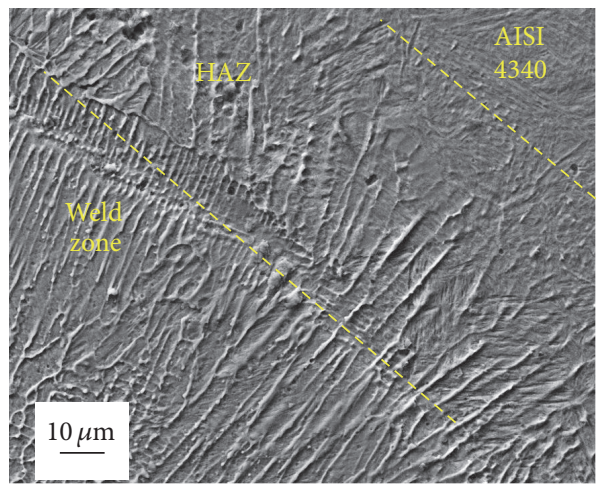

(c)

FIgURE 17: The HAZ of welded specimens: (a) AISI 316L side (sample number 3), (b) AISI 4340 side (sample number 3), and (c) AISI 4340 side (sample number 5).

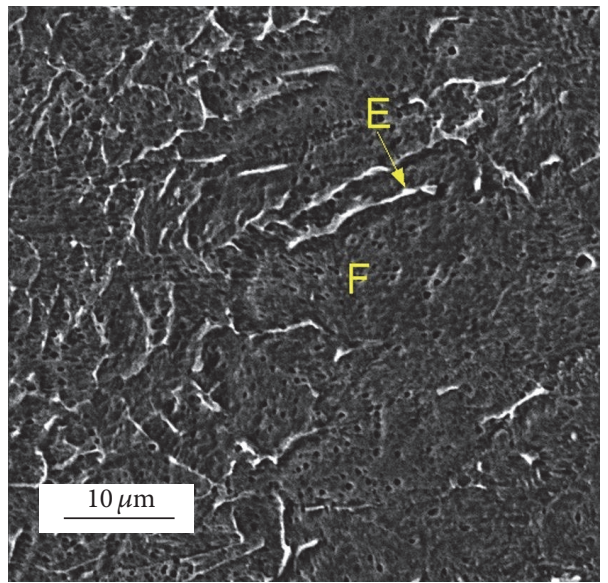

FIGURE 18: The selected region to detect Cr carbide in HAZ near AISI 316L base metal. 


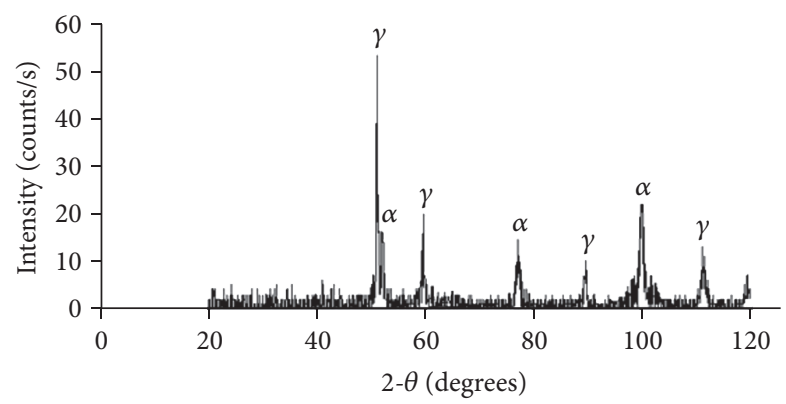

FIgURE 19: The XRD pattern from HAZ in 316L side for sample number 3 .

\section{Competing Interests}

The authors declare that there are no competing interests regarding the publication of this paper.

\section{References}

[1] Z. Sun and R. Karppi, "The application of electron beam welding for the joining of dissimilar metals: an overview," Journal of Materials Processing Technology, vol. 59, no. 3, pp. 257-267, 1996.

[2] J. M. Fragomeni and A. C. Nunes Jr., "A study of the effects of welding parameters on electron beam welding in the space environment," Aerospace Science and Technology, vol. 7, no. 5, pp. 373-384, 2003.

[3] C. Y. Ho, "Fusion zone during focused electron-beam welding," Journal of Materials Processing Technology, vol. 167, no. 2-3, pp. 265-272, 2005.

[4] N. Özdemir, F. Sarsılmaz, and A. Hasçalık, "Effect of rotational speed on the interface properties of friction-welded AISI 304L to 4340 steel," Materials \& Design, vol. 28, no. 1, pp. 301-307, 2007.

[5] A. Hasçalik, E. Ünal, and N. Özdemir, "Fatigue behaviour of AISI 304 steel to AISI 4340 steel welded by friction welding," Journal of Materials Science, vol. 41, no. 11, pp. 3233-3239, 2006.

[6] V. A. Ventrella, J. R. Berretta, and W. De Rossi, "Pulsed Nd:YAG laser seam welding of AISI 316L stainless steel thin foils," Journal of Materials Processing Technology, vol. 210, no. 14, pp. 18381843, 2010.

[7] B. Kurt, "The interface morphology of diffusion bonded dissimilar stainless steel and medium carbon steel couples," Journal of Materials Processing Technology, vol. 190, no. 1-3, pp. 138-141, 2007.

[8] M. Vedani, "Microstructural evolution of tool steels after NdYAG laser repair welding," Journal of Materials Science, vol. 39, no. 1, pp. 241-249, 2004.

[9] N. Arivazhagan, S. Singh, S. Prakash, and G. M. Reddy, "Investigation on AISI 304 austenitic stainless steel to AISI 4140 low alloy steel dissimilar joints by gas tungsten arc, electron beam and friction welding," Materials and Design, vol. 32, no. 5, pp. 3036-3050, 2011.

[10] A. Çalik, M. Karakas, and R. Varol, "Fatigue behavior of electron beam welded dissimilar metal joints," Welding Research, vol. 91, pp. 50-52, 2012.

[11] ASTM E8/E8M-08: Standard Test Techniques for Tension Testing of Metallic Materials, 2010.
[12] A. Krishnan, A. R. Poduri, and S. A. Reddy, "Effect of beam current, weld speed and dissolution on mechanical and microstructural properties in electron beam welding," International Journal of Research in Engineering and Technology, vol. 2, no. 6, pp. 1120-1129, 2013.

[13] M. Agilan, T. Venkateswaran, and D. Sivakumar, "Effect of heat input on microstructure and mechanical properties of inconel718 EB Welds," Procedia Materials Science, vol. 5, pp. 656-662, 2014.

[14] J. C. Lippold and D. J. Kotecki, Welding Metallurgy and Weldability of Stainless Steels, John Wiley \& Sons, Hoboken, NJ, USA, 2011.

[15] S. Kou, Welding Metallurgy, John Wiley \& Sons, New Jersey, NJ, USA, 2nd edition, 2003.

[16] J. M. Vitek, S. A. David, and C. R. Hinman, "Improved ferrite number prediction model that accounts for cooling rate effects-part 1: model development," Welding Journal, vol. 82, no. $1,2003$.

[17] J. W. Elmer, S. M. Allen, and T. W. Eagar, "Microstructural development during solidification of stainless steel alloys," Metallurgical Transactions A, vol. 20, no. 10, pp. 2117-2131, 1989. 

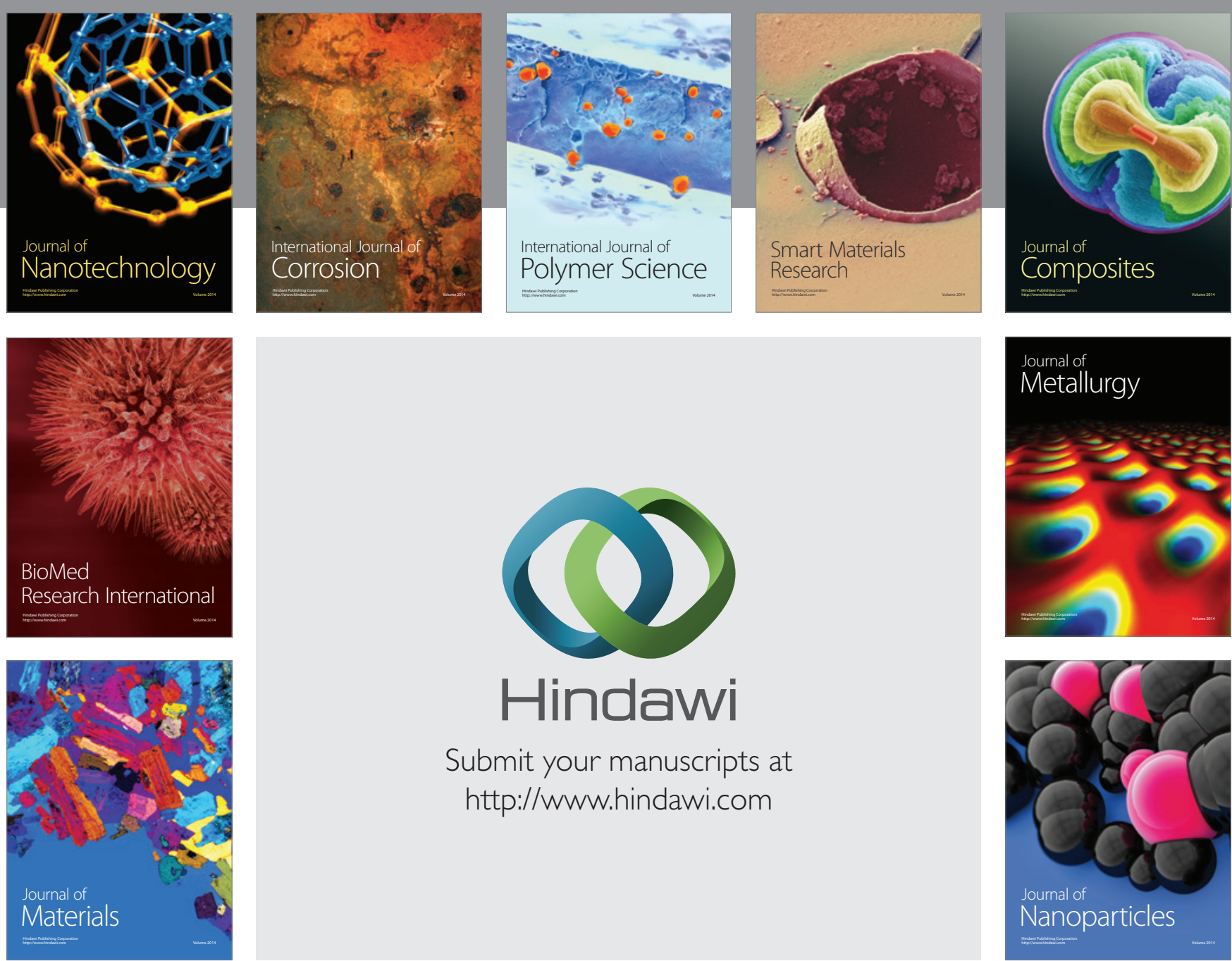

\section{Hindawi}

Submit your manuscripts at

http://www.hindawi.com

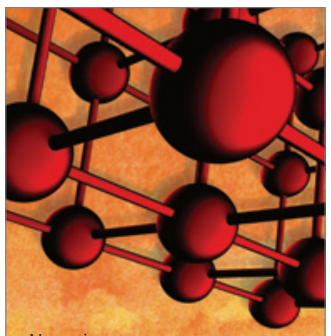

Materials Science and Engineering
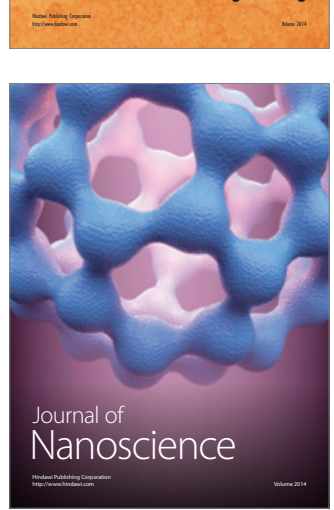
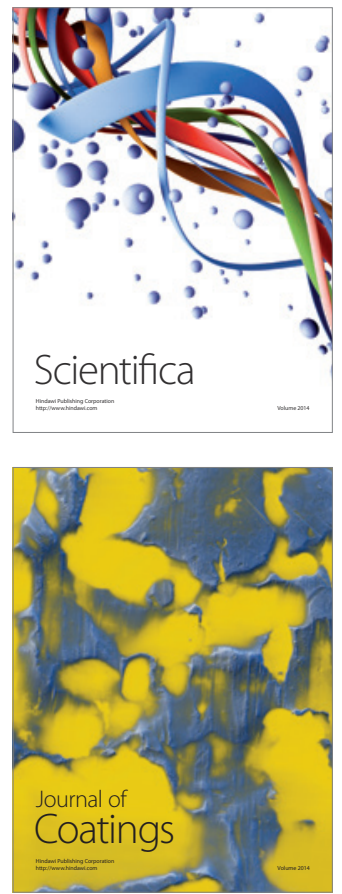
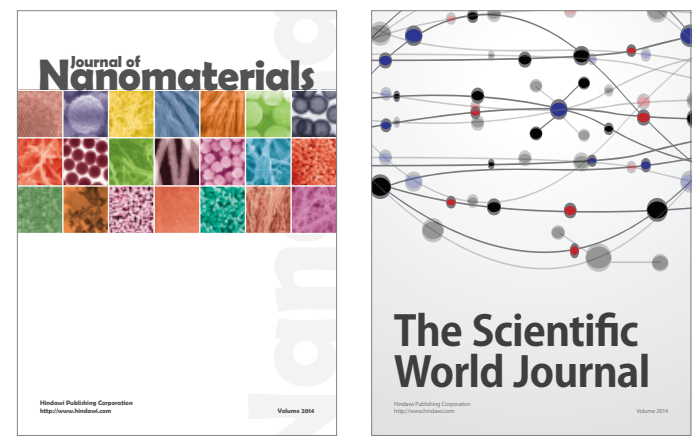

The Scientific World Journal
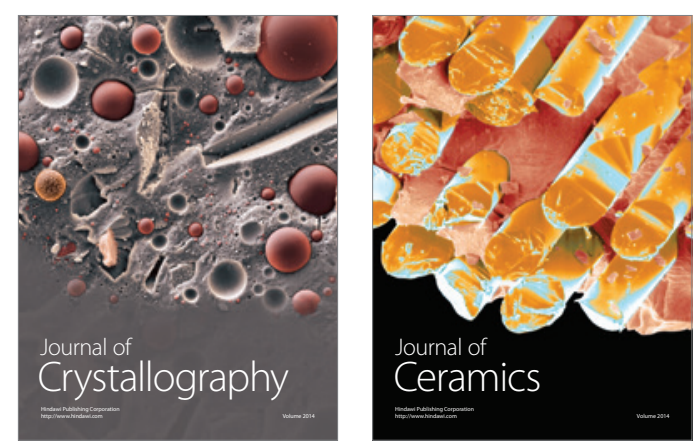
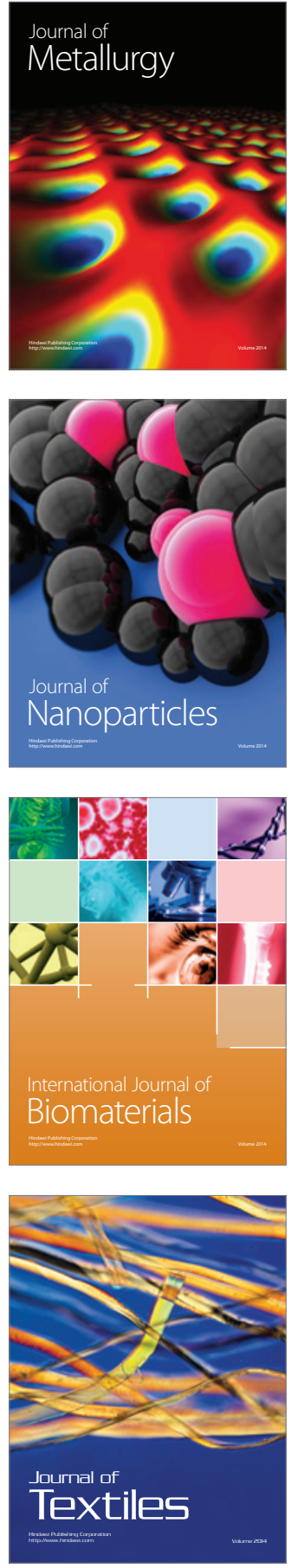